\title{
Influence of active versus passive parental presence on the behavior of preschoolers with different intelligence levels in the dental operatory: a randomized controlled clinical trial
}

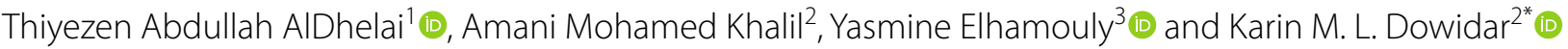

\begin{abstract}
Background: Dental fear and anxiety still pose the most common factors proposed for the child's negative behavior in the dental operatory. Intelligence has an impact on the children's communication, feelings, and responsiveness to dental situations. The benefits of parental presence on reinforcing the child's behavior during dental treatment are still debatable. This study aimed to assess the effect of parental active versus parental passive presence techniques on the overall behavior of preschool children with different intelligence levels.
\end{abstract}

Methods: This randomized controlled trial was conducted from December 2017 to August 2019. It recruited 150 healthy children, 3-6-year-old, with no history of previous dental pain/treatment, and intelligence quotient level of $70-\leq 110$ stratified into 3 equal groups (high, average, low). In the first visit, each IQ group was randomly divided into test (PAP) and control (PPP) groups. In the second visit, dental fear was assessed before preventive intervention, the test groups were then managed using parental active presence technique, while the control groups were managed using parental passive presence technique. The overall behavior was assessed at the end of the visit. Data was analyzed using Chi-square test and logistic regression analysis.

Results: The parental active presence technique had significant effect on children with high and low intelligence quotients. There were significantly higher odds of positive behavior in high than low intelligence quotient children, (OR 4.08, 95\% Cl 1.43, 11.67, P=0.01). The parental active presence technique had significantly higher odds of positive behavior than the parental passive presence technique, (OR 4.08, 95\% Cl 1.71, 9.76, $\mathrm{P}=0.002)$.

Conclusions: The parental active presence technique had positively influenced the children's overall behavior irrespective of their intelligence levels. This trial was retrospectively registered, trial identifier number: NCT04580316, $8 / 11 / 2020$

Keywords: Behavior modification, Intelligence quotient, Parental active/passive presence, Preschool children, Stanford Binet intelligence scale

*Correspondence: karin.dowidar@alexu.edu.eg

${ }^{2}$ Department of Pediatric Dentistry and Dental Public Health, Faculty

of Dentistry, Alexandria University, Alexandria, Egypt

Full list of author information is available at the end of the article

\section{Background}

Understanding children's development and behavior are crucial issues in pediatric dentistry [1]. Physical, social, emotional, and cognitive/intellectual developments are integrated and influence one another [2]. Different predictors were demonstrated for children's negative 
behavior in the dental setting. A strong correlation was proposed between dental fear and children's behavior so that it could be used as a behavior indicator in the dental setting $[3,4]$. Moreover, it was noted that the child's age was significantly related to his behavior; in which more negative behavior should be expected from younger children. Hence, age would be considered an influential factor in the overall behavior of children during dental treatment. Furthermore, female children were proposed to show higher levels of dental fear and thus negative behavior than that of male children [4]. Additionally, previous unpleasant dental experiences have been shown to influence the display of children's negative behavior in the dental clinic [1]. However, the exact reason why some children well behave in the dental operatory while others do not despite being under the same conditions is still not obvious. Therefore, it seems that another hidden factor, probably the cognitive factor, needs to be counted [5]. The Cognitive factor plays a major role in dental fear and anxiety (DFA) [6]. The correlation between children's intelligence and DFA, as well as their behavior in the dental clinic is a sensitive issue [7-11]. Children's behavior represents a great challenge in dental practice, as safe and effective treatment requires the shaping of the child and his parents' behaviors towards dental care. Hence, the term 'behavior guidance' has been developed. It entails that the dentist/dental team interact with the patient and the parents to allay DFA in order to establish a good rapport. This is needed for providing quality treatment and for encouraging a positive attitude towards oral health care [12].

Behavior management techniques must be integrated into an overall behavior guidance approach customized for each child. One of the proposed behavior management techniques is the parental presence/absence technique [12]. However, the benefits of this technique to the children during dental treatment are still conflicting [13]. Some studies have demonstrated that parental presence/ absence does not affect the child's anxiety or cooperation during dental sessions $[14,15]$.

On the other hand, it was reported that some dentists prefer to have the parents outside the operating room, as their presence may complicate communication with the child, or they may exhibit anxiety themselves [12]. Nevertheless, parental presence may be implemented to improve the children's behavior, especially for the young ones and those with limited cooperation, by helping them reduce their anxiety and cope with the new environment $[16,17]$.

Parental presence might be active or passive during dental treatment [18]. Involving the parent as a passive yet silent helper can provide a relaxing atmosphere without unnecessary interference [14]. However, if the parent is properly educated, he/she could actively act as a valuable adjunct in establishing rapport between the child and the dentist during treatment $[18,19]$.

Intelligence has a significant impact on children's communication, feelings, and responsiveness to dental situations [20]. Limited studies have dealt with the association between children's intelligence and their overall behavior in the dental clinic. The influence of parental presence/ absence on the children's behavior and fear during dental treatment has been abundantly evaluated in the literature [21]. However, to our knowledge, no evidence of research has investigated the effect of parental active versus passive presence technique on children's behavior in the dental setting. Therefore, this randomized controlled clinical trial was conducted to assess the effect of parental active and passive presence techniques (PAP/PPP) with tell-show-do (TSD) on the behavior of preschool children with different levels of intelligence. The null hypothesis was that there is no difference between the effect of PAP and PPP on the behavior of preschool children with different intelligence levels.

\section{Methods \\ Study design and study setting}

This parallel design randomized controlled clinical trial was set according to the CONSORT statement (Additional file 1) [22]. It was conducted in the outpatient clinic of the Pediatric Dentistry Department, Faculty of Dentistry, Alexandria University, Egypt, from December 2017 to August 2019. The PICO question was: In preschool children with different intelligence levels (P) how does parental active presence technique (I) compared to parental passive presence technique $(\mathrm{C})$ affect the overall behavior $(\mathrm{O})$ during preventive dental treatment?

\section{Sample size calculation}

The sample size was based on assuming 5\% alpha error, $20 \%$ beta error, allocation ratio between test and control groups of 1:1, and probability of positive behavior in the control group of low intelligence quotient (IQ) $=0.25$ [23]. An estimation was made of the probability of positive behavior in the test group with low IQ to have positive behavior as healthy children $=0.87$ [24]. So, to detect the difference between control and test groups, it was calculated that 9 children per group would be needed. [25] To ensure adequate power, we estimated a reduction in the difference between test and control groups regarding probabilities of positive behavior of $50 \%$ with the calculated required number $=24$. This was increased to 25 children per group to account for non-completion. Thus, the total required number of children $=$ number of IQ groups $\mathrm{X}$ number of intervention groups $\mathrm{X}$ number per intervention group $=3 \times 2 \times 25=150$ children. 


\section{Participants and ethics approval}

Participants enrolled in this study were healthy children, 3-6 years old, requiring preventive treatment, with no history of previous dental treatment or dental pain, and with IQ levels in the range of $70-\leq 110$. Children were excluded if they have pain, multiple dental problems, and history of medical and/or psychological problems. The study protocol (Additional file 2) was approved by the Research Ethics Committee, Faculty of Dentistry, Alexandria University, Egypt, (IRB 00010556)-(IORG 0008839). It was retrospectively registered at (https://clinicaltrials. gov), trial identifier number: NCT04580316, (8/11/2020). Prior to commencement, the study purpose, risks, and benefits were explained to the parents and a signed informed consent was obtained from the parents of all participants involved in the study.

\section{Randomization and allocation concealment}

Children were stratified based on their IQ level into 3 groups: high, average, and low IQ groups. In each group, children were randomly and equally allocated according to intervention into test (PAP) and control (PPP) groups. Randomization was performed by a trial independent person using a computer random number generator. Randomization sequence in blocks of 2 was created using random allocation software version 1.0.0 [26]. The allocated group was written on a piece of paper that was folded and enclosed in a sealed envelope that carried the child's name on its cover. At the time of intervention, an assistant opened the envelope, and identified the group to which the child was assigned.

\section{Intervention and study outcomes}

Prior to the study, intra-examiner reliability was assessed to ten children not participating in the study for the application of the facial image scale (FIS) and Frankl behavior rating scale (FBRS). These children were reevaluated after five days. The kappa values obtained were 0.71 and 0.73 respectively [27].

In the first visit, visual screening and comprehensive history taking were carried out to identify children who fulfilled the inclusion criteria. Children were stratified into 3 equal groups (50 children/group) by the same trained and certified operator according to their IQ level as follows: high IQ (HIQ) with scores above 110, average IQ (AIQ) with scores of 90-110, and low IQ (LIQ) with scores of 70-89. The IQ was measured using the Arabic version of the Stanford Binet intelligence scale, fourth edition (SB-IV) [28]. It is standardized for Arabic Egyptian norms and includes a wide verbal reasoning item that can lead to a valid strong verbal IQ [8]. The SB-IV is a flexible, easy-to-implement collection of tests presented in a form of photos, different colored cubes, cubic's blossom, beads, paper tests, and some guiding books. The test is grouped into four area scores: verbal reasoning, abstract/visual reasoning, quantitative reasoning, and short-term memory reasoning. Eight sub-tests (abbreviated test battery) were selected from the total 15 sub-tests (full test battery) of SB-IV scale according to the age group, and they were listed as follows: vocabulary (V); comprehension (Com); absurdities (Ab); pattern (P); copy (Cop); quantitative (Q); bead memory (BM); and memory for sentence (MS) [20, 29] The test was made by the researcher himself in a quiet closed room. Administration of the SB-IV scale typically takes between 30-90 min, and the parent of each child has attended the examination passively. Age-appropriate oral hygiene instructions were provided to the patient and his accompanying parent at the end of the visit.

In the second visit, dental fear (DF) was assessed before the intervention using FIS [30]. This scale consists of a row of five faces ranging from a very happy face to a very unhappy one. Children were asked to point at the face they mostly like at that moment. The face was scored by giving a value of (1) to the most positive effect face and (5) to the most negative face. Faces with values $(1,2)$ indicated low DF, value (3) indicated moderate DF, and faces with values $(4,5)$ indicated high DF [30].

In each IQ group, random allocation was performed so that 25 children were managed during intervention using PAP + TSD (test group), while the other 25 children (control group) were managed using PPP + TSD [31]. The PAP technique was implemented in this study in which the parents were allowed to stand close to their children, do handholding, eye contacting and help in explaining the dentist's instructions [16]. Conversely, in the PPP technique, parents were instructed to sit silently in the dental clinic behind the patient with no eye contact, and without a spoken word only to reassure their children. Non-pain provoking preventive measures were implemented including dental prophylaxis (Alpha-Pro ${ }^{\circledR}$ preventives Prophylaxis Past, Dental Technologies, Hamlin Avenue, Lincolnwood, Illinodis. USA) followed by fissure sealant (bioseal ${ }^{\circledR}$ Pit and Fissure Sealant, Biodinamica, Madrid. Spain), and/or topical fluoride application (Sorbet ${ }^{\circledR}$ Fluoride gel, Keystone Industries, Hollywood Avenue, Cherry Hill. USA).

\section{Outcome assessment}

The intervention was video recorded, and a blinded examiner evaluated the children's overall behavior in both groups using FBRS $[17,19]$ Rating $1(--)$ was given to the most negative child behavior and rating $4(++)$ to the most positive child behavior. The FBRS of $(3,4)$ were 
re-coded to positive behavior, while scores $(1,2)$ were recoded to negative behavior.

\section{Statistical analysis}

Descriptive statistics were calculated as frequencies and percentages. The comparison between test and control groups was done using Chi-squared test. Logistic regression models were used with adjustment for confounding factors (age, gender, and fear level) for better models' fit. The models assessed the effect of PAP and PPP and IQ levels on the outcome (behavior dichotomies into positive and negative behaviors). Wald Chi-square, their $\mathrm{p}$ values, estimates (OR), their 95\% confidence intervals (CI), and model adjusted Negelkerke $\mathrm{R}^{2}$ values were calculated. Intention to treat analysis was applied. Statistical analysis was done using SPSS version 17.0 (SPSS Inc., Chicago, Ill., USA). The significance level was set at $5 \%$.

\section{Results}

Out of 300 screened children, 150 were recruited (Fig. 1). The age range was divided into three groups. The 1st group ranged from $(3-<4)$ years, with $26.7 \%$ and $24 \%$ of the children in the PAP and PPP groups, respectively. The 2nd group ranged from $(4-<5)$ years, with $22.7 \%$ and $33.3 \%$ of the children in the PAP and PPP groups, respectively. The 3rd group ranged from (5-6) years, with 50.7\% and $42.7 \%$ of the children in the PAP and PPP groups, respectively. At baseline, there was no statistically significant difference in the distribution of children in the three age groups, $(P=0.34)$ nor in the intelligence quotient levels, $(\mathrm{P}=1.000)$ among the test and control groups. More

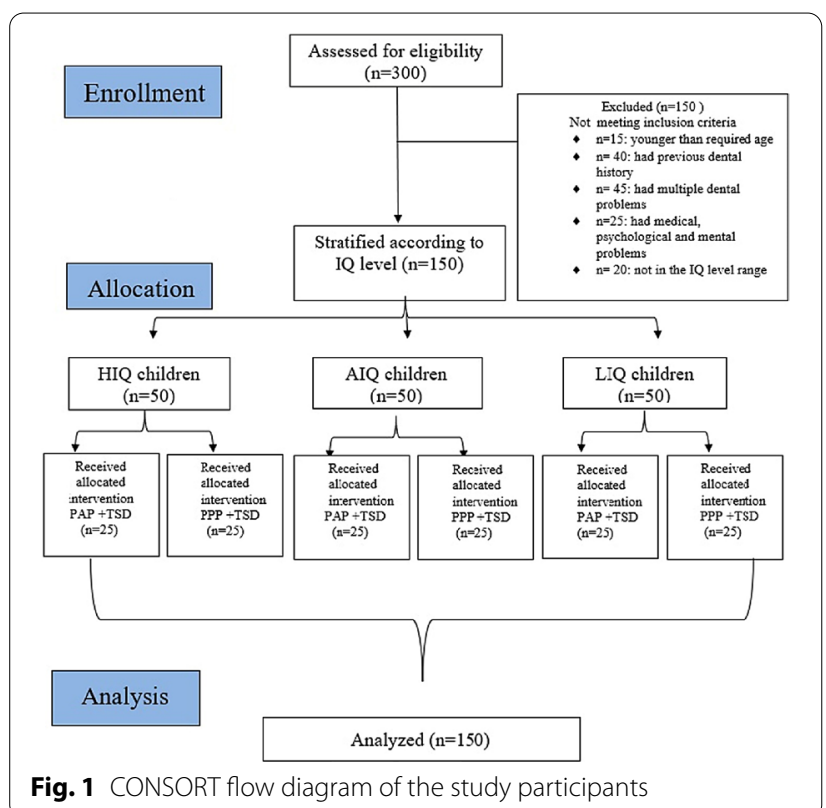

male children (60\%) were presented in the PAP group while more female children $(42.7 \%)$ were presented in the PPP group with no statistically significant difference, $(\mathrm{P}=0.74)$ between the study groups. More fearful children were presented in the PAP group (62.7\%) compared to the PPP group (48.0\%) with no significant difference in the FIS scores $(\mathrm{P}=0.71)$ between the test and control groups (Table 1).

Regarding the overall behavior after intervention, significantly more children in the test group (74.7\%) had positive behavior than in the control group (46.7\%), $(\mathrm{P}<0.0001)$ (Fig. 2). The mean FIS score

Table 1 Distribution of demographic variables, intelligence quotient, and fear levels among study groups before intervention

\begin{tabular}{llll}
\hline Factors & $\begin{array}{l}\text { PAP } \\
\mathbf{n}(\%) \\
\mathbf{N}=\mathbf{1 5 0} \text { children }\end{array}$ & $\begin{array}{l}\text { PPP } \\
\mathbf{n}(\%)\end{array}$ & P value \\
& & & \\
\hline Age & & \\
$3-<4$ years & $20(26.7 \%)$ & $18(24 \%)$ & 0.34 \\
$4-<5$ years & $17(22.7 \%)$ & $25(33.3 \%)$ & \\
$5-6$ years & $38(50.7 \%)$ & $32(42.7 \%)$ & \\
Gender & & & \\
Male & $45(60.0 \%)$ & $43(57.3 \%)$ & 0.74 \\
Female & $30(40.0 \%)$ & $32(42.7 \%)$ & \\
Intelligence quotient & & & \\
HIQ & $25(33.3 \%)$ & $25(33.3 \%)$ & 1.000 \\
AlQ & $25(33.3 \%)$ & $25(33.3 \%)$ & \\
LIQ & $25(33.3 \%)$ & $25(33.3 \%)$ & \\
Fear & & & \\
Unfearful & $28(37.3 \%)$ & $39(52.0 \%)$ & 0.71 \\
Fearful & $47(62.7 \%)$ & $36(48.0 \%)$ & \\
\hline
\end{tabular}

${ }^{*}$ Statistically significant at $\mathrm{P}<0.05$

$H I Q$ high intelligence quotient group, $A / Q$ average intelligence quotient group, $L I Q$ low intelligence quotient group, PAP parental active presence, $P P P$ parental passive presence

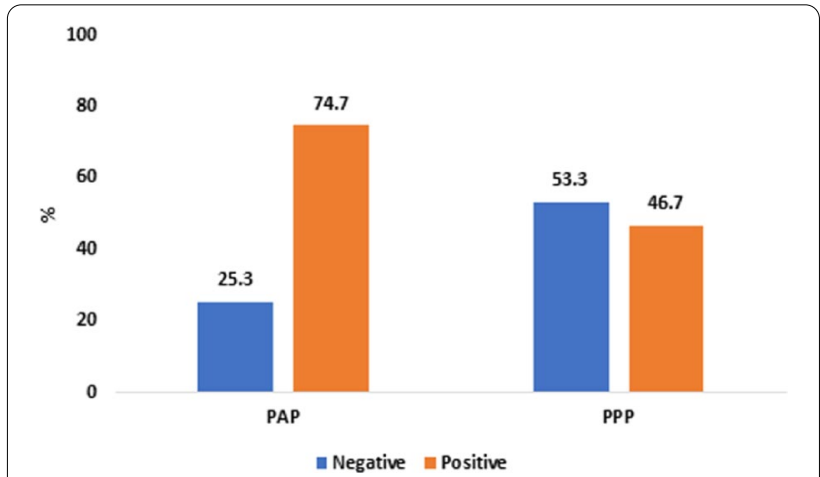

Fig. 2 Children's overall behavior among the study group after intervention 
before intervention was $2.16 \pm 1.18$ for the HIQ group, $2.04 \pm 1.12$ for the AIQ group, and $3.00 \pm 1.34$ for the LIQ group.

Table 2 displays the logistic regression model for positive behavior as a dependent variable across the intelligence level and intervention. Intelligence had a significant effect on positive behavior. Children with HIQ had significantly higher odds of positive behavior compared to children with LIQ whereas children with AIQ did not differ significantly from children with LIQ as regards to positive behavior $(\mathrm{P}=0.01$ and 0.09 respectively). The odds for positive behavior were 4.08-fold significantly higher in the PAP technique compared to PPP technique, (OR 4.08, 95\% CI 1.71, 9.76, $\mathrm{P}=0.002$ ) after adjustment for age, gender, and fear levels. The model goodness of fit indicated a good overall performance. $\left(R^{2}=0.601\right)$.

Three logistic regression models assessing the effect of intervention on positive behavior for each intelligence level are shown in Table 3. The odds for positive behavior were 13.17-fold higher in the HIQ group children managed with the PAP technique than children managed with the PPP technique (OR 13.17, 95\% CI 1.33, 130.74, $P=0.03)$. Similarly, in the LIQ group, 4.14-fold significantly higher odds were found among the children managed with the PAP technique compared to the children managed with the PPP technique (OR 4.14, 95\% CI 1.05,

Table 2 Logistic regression model assessing the effect of children's intelligence levels and intervention on positive behavior

\begin{tabular}{lcllll}
\hline Variables & Wald X & P value & OR & \multicolumn{2}{l}{$\mathbf{9 5 \%}$ Cl for OR } \\
\cline { 5 - 6 } & & & & Lower & Upper \\
\hline HIQ vs LIQ & 6.89 & $0.01^{*}$ & 4.08 & 1.43 & 11.67 \\
AIQ vs LIQ & 2.81 & 0.09 & 2.40 & 0.86 & 6.68 \\
PAP vs PPP & 10.01 & $0.002^{*}$ & 4.08 & 1.71 & 9.74 \\
\hline
\end{tabular}

${ }^{*}$ Statistically significant at $\mathrm{P}<0.05$

$H I Q$ high intelligence quotient group, $A I Q$ average intelligence quotient group, LIQ low intelligence quotient group, PAP parental active presence, PPP parental passive presence. Children's overall behavior was adjusted for age, gender, and fear level. Wald $\mathrm{X}^{2}$ : Wald Chi square test. OR odds ratio, $95 \% \mathrm{Cl}$ confidence interval
16.26, $P=0.04)$.The odds of positive behavior in the AIQ children managed with the PAP technique was 1.45 times more than those managed with the PPP technique; however, the difference was not statistically significant. (OR 1.45, 95\% CI 0.29, 7.26, $P=0.65$ ). All models were adjusted for age, gender, and fear levels. The adjusted $R^{2}$ values were $0.543,0.521$, and 0.503 for HIQ, AIQ, and LIQ models, respectively.

\section{Discussion}

This study was performed to determine the effect of parental active and passive presence techniques on the overall behavior of children with different intelligence levels in the dental clinic. Children with different IQ levels who were managed with the PAP technique showed higher overall positive behavior in the dental setting compared to those managed with the PPP technique. Hence, the null hypothesis was rejected.

In correspondence to previous studies $[5,6,10]$, the results of this study showed that HIQ children were significantly cooperative during dental treatment compared to LIQ children. Moreover, the PAP technique significantly reinforced the children's positive behavior compared to the PPP technique. The active parental participation helped in alleviating the anxiety induced by their overactive minds due to negative perceptions and anticipated threats that might occur in the dental environment [32].

In the present study, it was observed that LIQ children showed more negative behavior in the dental setting. They were scared, unsecured, and tried to avoid any contact with the dentist, despite the non-painprovoking intervention that was carried out to eliminate the pain-induced fear. This could be referred to the LIQ being a constant risk factor for the appearance and continuity of low self-esteem and anti-social behavior in the course of life [33]. This observation goes along with previous studies $[5,8,9]$ which reported that LIQ children probably needed significantly longer time to accept the dental treatment, thus expressed negative behavior. However, it contradicts other studies that observed inverse [34] or no correlation [10].

Table 3 Logistic regression models assessing the relation between intervention and positive behavior per study group

\begin{tabular}{|c|c|c|c|c|c|c|}
\hline \multirow[t]{2}{*}{ Groups } & \multirow[t]{2}{*}{ Variables } & \multirow[t]{2}{*}{ Wald X } & \multirow[t]{2}{*}{$P$ value } & \multirow[t]{2}{*}{ OR } & \multicolumn{2}{|c|}{$95 \% \mathrm{Cl}$ for OR } \\
\hline & & & & & Lower & Upper \\
\hline HIQ & PAP vs PPP & 4.85 & $0.03^{*}$ & 13.17 & 1.33 & 130.74 \\
\hline AIQ & PAP vs PPP & 0.21 & 0.65 & 1.45 & 0.29 & 7.26 \\
\hline LIQ & PAP vs PPP & 4.13 & $0.04^{*}$ & 4.14 & 1.05 & 16.26 \\
\hline
\end{tabular}

"Statistically significant at $\mathrm{P}<0.05$. HIQ high intelligence quotient group, A/Q average intelligence quotient group, LIQ low intelligence quotient group, PAP parental active presence, $P P P$ parental passive presence. Children's overall behavior was adjusted for age, gender, and fear level. Wald $X^{2}:$ Wald Chi square test. OR odds ratio, $95 \% \mathrm{Cl}$ confidence interval 
Nevertheless, the application of the PAP technique was shown to influence the positive behavior of LIQ children significantly as the parents helped by explaining the procedure and the dentist's instructions and by reassuring the children with physical contact.

The effect of PAP/PPP techniques on the behavior of AIQ children was not significantly displayed in the current study. This could be attributed to some factors that were proposed to impact the children's behavior including parents' intelligence quotient [35], parenting styles [36] and anxiety [37], and children's emotional quotient [10]. It could be hypothesized that the behavior of AIQ children was coincidentally influenced by some or a combination of these factors. Accordingly, the effect of the PAP/PPP techniques was hindered.

The present study calls attention to the value of recognizing the children's IQ as a predictor of their behavior. Moreover, it highlights the remarkable effect of active parental participation on the children's positive behavior in the dental environment, hence; assists the pediatric dentist in providing the needed quality dental care.

To our knowledge, this is the first clinical trial that has assessed the effect of the PAP/PPP techniques on the overall behavior of children with adjustment of age, gender, and fear levels. However, the limitation imposed by this trial was not assessing the parenting styles and parental anxiety in relation to the children's behavior in the dental operatory. Consequently, further studies are needed to evaluate the effects of these relationships and to evaluate the effectiveness of the PAP/PPP techniques with more pain-provoking dental procedures.

\section{Conclusions}

The PAP technique had positively influenced the children's overall behavior with different intelligence levels. High IQ children showed more positive behavior than LIQ children who had shown more dental fear in the dental setting.

\section{Abbreviations \\ DFA: Dental fear and anxiety; PAP: Parental active presence; PPP: Parental passive presence; TSD: Tell-show-do; IQ: Intelligence quotient; FIS: Facial image scale; FRBS: Frankl behavior rating scale; HIQ: High intelligence quotient; AIQ: Average intelligence quotient; LIQ: Low intelligence quotient; SB-IV: Stanford Binet intelligence scale, fourth edition; DF: Dental fear; OR: Odds ratio; Cl: Confidence interval.}

\section{Supplementary Information}

The online version contains supplementary material available at https://doi. org/10.1186/s12903-021-01781-z.

Additional file 1: CONSORT checklist.

Additional file 2: Study protocol.

\section{Acknowledgements}

The authors are indebted to Prof. Maha El Tantawi, Professor of Dental Public Health, Department of Pediatric Dentistry and Dental Public Health, Faculty of Dentistry, Alexandria University, Egypt, for performing the sample size calculation, randomization, allocation, and the statistical analysis of this study. The authors are also grateful to Prof. Mahmoud Abdel Halim Mansy, Department of Educational Psychology, Faculty of Education, Alexandria University, Egypt, for his great help with the study methods.

\section{Authors' contributions}

TAA conceptualized the study, performed the clinical procedure, collected, and interpreted data, prepared the manuscript draft. AMK conceptualized the study and helped with the study design.YE interpreted the data, edited, and prepared the final manuscript. KMLD conceptualized the study, helped with the study design, and supervised the clinical procedure. All authors read and approved the final manuscript.

Funding

There was no funding to support this research.

\section{Availability of data and materials}

The datasets used and/or analyzed during the current study are available from the corresponding author on reasonable request.

\section{Declarations}

\section{Ethics approval and consent to participate}

Prior to the commencement of the study, ethical approval was obtained from the Research Ethics Committee at the Faculty of Dentistry, Alexandria University, Egypt, (IRB 00010556 - IORG 0008839). All methods were performed in accordance with the relevant guidelines and regulations. An informed written consent was obtained from the parents of all participants involved in the study.

\section{Consent for publication}

Not applicable.

\section{Competing interests}

The authors declare that they have no competing interests.

\section{Author details}

${ }^{1}$ Department of Orthodontics and Pediatric Dentistry, College of Dentistry, Qassim University, Buraydah, Saudi Arabia. ${ }^{2}$ Department of Pediatric Dentistry and Dental Public Health, Faculty of Dentistry, Alexandria University, Alexandria, Egypt. ${ }^{3}$ Pediatric and Community Dentistry Department, Faculty of Dentistry, Pharos University in Alexandria, Alexandria, Egypt.

Received: 10 March 2021 Accepted: 12 August 2021

Published online: 28 August 2021

References

1. Kumar D, Anand A, Aggarwal N, Sharma A, Mittal V, Singh A. Factors predicting behavior management problems during initial dental examination in children aged 2 to 8 years. Int J Clin Pediatr Dent. 2017;10:5-9.

2. McCartney K, Phillips D. Handbook of early child development. Oxford: Blackwell Science; 2006.

3. Kakkar M, Wahi A, Thakkar R, Vohra I, Shukla AK. Prevalence of dental anxiety in 10-14 years old children and its implications. J Dent Anesth Pain Med. 2016;16:199-202.

4. Cianetti S, Lombardo G, Lupatelli E, Pagano S, Abraha I, Montedori A, et al. Dental fear/anxiety among children and adolescents A systematic review. Eur J Paediatr Dent. 2017;18:121-30.

5. Rud B, Kisling E. The influence of mental development on children's acceptance of dental treatment. Eur J Oral Sci. 1973;81:343-52.

6. Carrillo-Diaz M, Crego A, Armfield JM, Romero-Maroto M. Treatment experience, frequency of dental visits, and children's dental fear: a cognitive approach. Eur J Oral Sci. 2012;120:75-81. 
7. Toledano M, Osorio R, Aguilera F, Pegalajar J. Children's dental anxiety: influence of personality and intelligence factors. Int J Paediatr Dent. 2009:5:23-8.

8. Blomqvist M, Ek U, Fernell E, Holmberg K, Westerlund J, Dahllöf G. Cognitive ability and dental fear and anxiety. Eur J Oral Sci. 2013;121:117-20.

9. Thomson WM, Broadbent JM, Caspi A, Poulton R, Moffitt TE. Childhood $<\mathrm{scp}>\mid \mathrm{Q}</ \mathrm{scp}>$ predicts age-38 oral disease experience and service-use. Community Dent Oral Epidemiol. 2019;47:252-8.

10. Aminabadi NA, Erfanparast $L$, Ebrahim ZA, Maljaii E, Ranjbar F, Jamali Z The impact of emotional intelligence and intelligence quotient (IQ) on child anxiety and behavior in the dental setting. Acta Odontol Scand. 2011;69:292-8

11. Shetty RM, Pashine A, Jose NA, Mantha S. Role of Intelligence Quotient (IQ) on anxiety and behavior in children with hearing and speech impairment. Spec Care Dent. 2018;38:13-8.

12. Feigal RJ. Guiding and managing the child dental patient: a fresh look at old pedagogy. J Dent Educ. 2001;65:1369-77.

13. Piira T, Sugiura T, Champion GD, Donnelly N, Cole ASJ. The role of parenta presence in the context of children's medical procedures: a systematic review. Child Care Health Dev. 2005:31:233-43.

14. Afshar H, Baradaran Nakhjavani $Y$, Mahmoudi-Gharaei J, Paryab M, Zadhoosh S. The effect of parental presence on the 5 year-old children's anxiety and cooperative behaviour in the first and second dental visit. Iran J Pediatr. 2011;21:193-200.

15. Boka V, Arapostathis K, Charitoudis G, Veerkamp J, van Loveren C, Kotsanos N. A study of parental presence/absence technique for child dental behaviour management. Eur Arch Paediatr Dent. 2017;18:405-9.

16. Kotsanos N, Coolidge T, Velonis D, Arapostathis KN. A form of 'parental / absence' (PPA) technique for the child patient with dental behaviour management problems. Eur Arch Paediatr Dent. 2009;10:90-2.

17. Riba H, Al-Shahrani A, Al-Ghutaimel H, Al-Otaibi A, Al-Kahtani S. Parental presence/absence in the dental operatory as a behavior management technique: a review and modified view. J Contemp Dent Pract. 2018;19:237-41.

18. Pinkham JR. An analysis of the phenomenon of increased parental participation during the child's dental experience. ASDC J Dent Child. 1991;58:458-63.

19. FrankI S, Shiere FFH. Should the parent remain with the child in the dental operatory. J Dent Child. 1962;29:150-63.

20. Thorndike R, Hagen E, Sattler J. Stanford-Binet Intelligence Scale-Fourth Edition: guide for administration and scoring. Chicago: Riverside publishing company; 1986

21. De Luca MP, Massignan C, Bolan M, Oliveira LB, Aydinoz S, Dick B, De Luca CG. Does the presence of parents in the dental operatory room influence children's behavior, anxiety and fear during their dental treatment? A systematic review. Int J Paediatr Dent. 2020. https://doi.org/10.1111/ipd. 12762.

22. Schulz KF, Altman DG, Moher D. CONSORT 2010 statement: updated guidelines for reporting parallel group randomised trials. BMC Med. 2010;8:18.

23. Fields $\mathrm{H}$, Pinkham J. Videotape modeling of the child dental patient. J Dent Res. 1976:55:958-63.

24. Peretz B, Gluck G. Magic trick: a behavioural strategy for the management of strong-willed children. Int J Paediatr Dent. 2005;15:429-36.

25. The University of British Columbia:sample size calculator for comparing two proportional means. https://www.stat.ubc.ca/ rollin/statsssize/b2. html. (2017) Accessed 22 October 2017.

26. Saghaei M. Random allocation software for parallel group randomized trials. BMC Med Res Methodol. 2004;4:26.

27. Kayapınar U. Measuring essay assessment: Intra-rater and inter-rater reliability. Eurasian J Educ Res. 2014;57:113-36.

28. Kamel ML. Stanford-Binet Intelligence Scale-Record Booklet. 4th ed. Cairo: Dar Al Nahdah Al Arabia; 1998.

29. Reynolds CR, Kamphaus RW. Handbook of psychological and educational assessment. New York: Gulliford; 2003.

30. Buchanan H, Niven N. Validation of a Facial Image Scale to assess child dental anxiety. Int J Paediatr Dent. 2002;12:47-52.

31. Addelston H. Child patient training. Rev Chicago Dent Soc Fort. 1959:9:27-9.

32. DiBona $\mathrm{M}$. The relationship between fear and intelligence in the child patient. NY J Dent. 1973;43:52-6.

33. Morgan AG, Rodd HD, Porritt JM, Baker SR, Creswell C, Newton T, et al. Children's experiences of dental anxiety. Int J Paediatr Dent. 2017:27:87-97

34. Koenen KC, Caspi A, Moffitt TE, Rijsdijk F, Taylor A. Genetic influences on the overlap between low IQ and antisocial behavior in young children. J Abnorm Psychol. 2006;115:787-97.

35. Whitley E, Gale CR, Deary IJ, Kivimaki M, Batty GD. Association of maternal and paternal IQ with offspring conduct, emotional, and attention problem scores: transgenerational evidence from the 1958 British birth cohort study. Arch Gen Psychiatry. 2011;68:1032-8.

36. Wood JJ, MCLeod BD, Sigman M, Hwang WC, Chu BC. Parenting and childhood anxiety: theory, empirical findings, and future directions. J Child Psychol Psychiatry. 2003:44:134-51.

37. Fazli M, Kavandi MR. Parents's anxiety on children cooperation at dental visit. Procedia Soc Behav Sci. 2015;205:117.

\section{Publisher's Note}

Springer Nature remains neutral with regard to jurisdictional claims in published maps and institutional affiliations.
Ready to submit your research? Choose BMC and benefit from:

- fast, convenient online submission

- thorough peer review by experienced researchers in your field

- rapid publication on acceptance

- support for research data, including large and complex data types

- gold Open Access which fosters wider collaboration and increased citations

- maximum visibility for your research: over $100 \mathrm{M}$ website views per year

At $\mathrm{BMC}$, research is always in progress.

Learn more biomedcentral.com/submissions 